\title{
Classical versus alternative macrophage activation: the Ying and the Yang in host defense against pulmonary fungal infections
}

\author{
CM Leopold Wager ${ }^{1,2}$ and FL Wormley $\mathrm{Jr}^{1,2}$
}

Macrophages are innate immune cells that possess unique abilities to polarize toward different phenotypes. Classically activated macrophages are known to have major roles in host defense against various microbial pathogens, including fungi, while alternatively activated macrophages are instrumental in immune-regulation and wound healing.

Macrophages in the lungs are often the first responders to pulmonary fungal pathogens, and the macrophage polarization state has the potential to be a deciding factor in disease progression or resolution. This review discusses the distinct macrophage polarization states and their roles during pulmonary fungal infection. We focus primarily on Cryptococcus neoformans and Pneumocystis model systems as disease resolution of these two opportunistic fungal pathogens is linked to classically or alternatively activated macrophages, respectively. Further research considering macrophage polarization states that result in anti-fungal activity has the potential to provide a novel approach for the treatment of fungal infections.

\section{INTRODUCTION}

In the past few decades, the prevalence of fungal disease has increased. Multiple medically important respiratory fungal infections begin with the inhalation of the infectious propagule into the lungs where, in immunocompetent individuals, the fungus is often cleared or controlled by the host's immune system. ${ }^{1}$ However, infection with several fungal pathogens, including Histoplasma capsulatum, Blastomyces dermatitidis, and Cryptococcus neoformans, can cause potentially fatal disease in immunocompromised individuals, including those with AIDS and those undergoing immunosuppressive therapies. $^{2-5}$ Therefore, the ability of the host's immune system to eradicate or limit the spread of fungal pathogens from the lungs is vitally important.

Macrophages are innate immune cells that have critical roles in protection against pulmonary fungal pathogens, including C. neoformans, Aspergillus fumigatus, Pneumocystis, B. dermatitidis, and Paracoccidioides brasiliensis. ${ }^{6-13}$ Although patients infected with what are classically considered opportunistic infections, such as C. neoformans, A. fumigatus, and Pneumocystis, rely more heavily on innate immunity when they are
$\mathrm{T}$ celll deficient, studies suggest that protective responses against the primary pulmonary fungal pathogens in immunocompetent individuals also depend on innate immunity. ${ }^{14}$ Macrophages are a unique cell type as they can differentiate into multiple phenotypes with different roles: wound healing, immune regulation, and host defense. ${ }^{15,16}$ The purpose of this review is to demonstrate the critical role classically and alternatively activated macrophages have during respiratory fungal infections and how the outcome of infection can be determined by the macrophages' ability to polarize in a way that supports resolution and not exacerbation of disease.

\section{TISSUE-RESIDENT AND INFILTRATING MACROPHAGES}

Resident alveolar macrophages reside within the lung alveolar airspaces and are often the first line of defense against pulmonary pathogens, making them critical to host defense in pulmonary tissues. ${ }^{17}$ Resident murine alveolar macrophages are classified as $\mathrm{CD} 45^{+} / \mathrm{CD} 68^{\mathrm{hi}} / \mathrm{F} 4 / 80^{+} / \mathrm{CD} 11 \mathrm{~b}^{-} / \mathrm{CD} 11 \mathrm{c}^{+} /$ $\mathrm{Gr}^{-}$while lung interstitial macrophages are categorized as $\mathrm{CD} 45^{+} / \mathrm{CD} 68^{\mathrm{lo}} / \mathrm{CD} 11 \mathrm{~b}^{+} / \mathrm{Gr} 1^{-}$and express $\mathrm{CD} 11 \mathrm{c}$ and low concentrations of F4/80. ${ }^{18}$ Alveolar macrophages also express

${ }^{1}$ Department of Biology, The University of Texas at San Antonio, San Antonio, Texas, USA and ${ }^{2}$ The South Texas Center for Emerging Infectious Diseases, The University of Texas at San Antonio, San Antonio, Texas, USA. Correspondence: FL Wormley (floyd.wormley@utsa.edu)

Received 11 March 2014; accepted 21 June 2014; published online 30 July 2014. doi:10.1038/mi.2014.65 
DEC205 and Siglec-F; however, these markers are not exclusive to macrophages and have not been detected on macrophages from other tissues. ${ }^{19-21}$ (An in-depth discussion of the characteristics and plasticity of alveolar macrophages is reviewed elsewhere. ${ }^{19}$ ) Infiltrating macrophages express high levels of CD11b and Ly6C, are F4/80 ${ }^{+} / \mathrm{CD} 11 \mathrm{c}^{-}$, and produce pro-inflammatory cytokines, such as tumor necrosis factor- $\alpha$ $(\mathrm{TNF}-\alpha)$ and interferon- $\gamma($ IFN- $\gamma){ }^{22,23}$ Recent fate mapping studies have revealed that tissue-resident lung macrophages and other tissue-resident macrophages, including liver Kupffer cells, splenic, and peritoneal macrophages, have origins established before the birth of the organism. ${ }^{24}$ Tissue-resident lung macrophages do appear to be of mixed origin. For example, $\mathrm{F} 4 / 80^{\mathrm{hi}}$ macrophages, which have a gene signature common to yolk sac macrophages, can persist in adult mice independently of hematopoietic stem cells and transcription factor $M y b$; however, $\mathrm{CD} 11 \mathrm{~b}^{\mathrm{hi}} / \mathrm{F} 4 / 80^{\mathrm{lo}}$ and some $\mathrm{F} 4 / 80^{\mathrm{hi}}$ macrophages are continuously replaced by $M y b$-dependent bone marrow precursors. ${ }^{25} \mathrm{~A}$ variety of tissue-resident macrophages, including microglia, lung, and peritoneal macrophages, have been shown to self-renew throughout the adult life of mice during steady state in a macrophage colony-stimulating factor (M-CSF/CSF-1) and granulocyte-macrophage (GM)-CSF (CSF-2)-dependent manner. ${ }^{26}$

Following the release of cytokines by resident alveolar macrophages, circulating mononuclear phagocytes infiltrate into the lungs. ${ }^{27}$ Recruited monocytes are generally divided into two main subsets: Ly6Chi/CC-chemokine receptor 2 (CCR2) ${ }^{+}$ and $\mathrm{Ly} 6 \mathrm{C}^{\mathrm{lo}} / \mathrm{CX} 3 \mathrm{C}$-chemokine receptor 1 (CX3CR1) (ri $^{\mathrm{hi}}$ (reviewed in Mosser and Edwards, ${ }^{15}$ Shi and Pamer, ${ }^{23}$ and Gordon and Taylor ${ }^{28}$ ). CCR2, macrophage chemoattractant protein-1 (MCP-1)/CCL2, and MCP-3/CCL7 are critical for the egress of monocytes from the bone marrow and maintenance of normal blood monocyte counts during steady state and infection. ${ }^{29-31}$ Deficiency of CCR2 in mice during pulmonary infection with $C$. neoformans results in decreased monocyte recruitment and subsequent differentiation into macrophages in the lungs and the development of a non-protective Th2-type immune response in the chronic infection model, thereby demonstrating the importance of infiltrating monocytes/ macrophages for protection. ${ }^{32}$ In a disease setting, it is difficult to distinguish between tissue-resident lung macrophages and infiltrating macrophages; therefore further study is necessary to effectively differentiate between these subsets of macrophages. Determination of the roles played by each subset during the stages of a protective immune response, including the initiation of inflammation and the return to steady state, could facilitate the development of novel therapies that take advantage of the intrinsic roles of these cells.

\section{MACROPHAGE ACTIVATION}

Alveolar and infiltrating macrophages are able to phagocytize and kill invading pathogens and present antigen to activated $\mathrm{T}$ cells to further stimulate an adaptive immune response in immunocompetent individuals. A primary role of macrophages is to clear the cellular debris generated during tissue remodeling and apoptosis. During these activities, macrophages can detect danger signals through their pattern-recognition receptors, such as Toll-like receptors (TLRs) and C-type lectin receptors (CLRs). These danger signals include pathogen-associated molecular patterns on the invading organisms and damageassociated molecular patterns, which occur as the infection progresses and cells are damaged. ${ }^{14,33,34}$ Macrophages have a plasticity that allows them to respond to changes in their microenvironment by altering their activation phenotype resulting in the broad classification of classical (M1) or alternative (M2) macrophage activation. ${ }^{15,35,36}$ Following TLR and CLR recognition of invading microorganisms, immune cells respond by secreting inflammatory cytokines, including IFN- $\gamma$, resulting in macrophage polarization toward an M1 phenotype (Figure 1). ${ }^{15,16,19,37}$ Macrophage activation phenotypes are identified by hallmark markers, including cytokines and chemokines secreted by the activated macrophages that can induce leukocyte recruitment and aid in the resolution of infection. ${ }^{15,16}$ Many M1 markers are induced/upregulated by IFN- $\gamma$, which is secreted by innate and adaptive immune cells, including natural killer (NK) cells, $\mathrm{CD}^{+}{ }^{-} \mathrm{T}$ cells, and $\mathrm{CD} 4^{+}$ T helper type 1 (Th1)-type T cells. ${ }^{15}$ Monocytes/macrophages stimulated with IFN- $\gamma$ and lipopolysaccharide or lipopolysaccharide alone in humans or IL-12 and IL-18 in mice are subsequently capable of producing IFN- $\gamma^{38,39}$ Studies in our laboratory examining M1-polarized macrophages have also led to the observation of IFN- $\gamma$ gene expression in murine lung macrophages during anti-cryptococcal immune responses. ${ }^{6}$

The markers commonly used for identification of M1 macrophages include inducible nitric oxide synthase (iNOS) or nitric oxide synthase 2 , chemokine (C-X-C motif) ligand 9 (CXCL9), CXCL10, CXCL11, IL-12, and suppressor of cytokine signaling 3 (SOCS3). ${ }^{15,40}$ CXCL9, CXCL10, and CXCL11 are chemokines that bind to a common receptor, CXCR3, and this binding results in leukocyte trafficking of principally $\mathrm{CD} 4^{+}$ Th1-type T cells, $\mathrm{CD} 8{ }^{+} \mathrm{T}$ cells, and NK cells. ${ }^{41}$ SOCS3 restricts responsiveness to IL-4, resulting in downregulation of M2 macrophage activation markers, and promotes pro-inflammatory responses. ${ }^{42,43}$

M1 macrophages mediate host defense against foreign pathogens by microbicidal activity, including the generation of reactive oxygen and nitrogen species (ROS and RNS, respectively). ${ }^{44}$ The enzyme iNOS acts on the substrate L-arginine to produce nitric oxide (NO), which has anti-bacterial and antifungal properties. Molecules common to fungal organisms$\beta$-glucan in fungal cell walls and zymosan, a $\beta$-glucan-rich cell wall particle prepared from Saccharomyces cerevisiae-can stimulate the production of ROS in macrophages via Dectin-1, a CLR that recognizes $\beta$-glucans, with and without the collaboration of TLRs. ${ }^{45,46}$ Dectin-1, along with Dectin-2, a CLR capable of $\alpha$-mannan recognition, helps mediate protection against multiple fungal infections, including Coccidioides, ${ }^{47,48}$ Pneumocystis, ${ }^{49}$ and Candida. ${ }^{45,50}$ These receptors are found on various immune cells, including monocytes/macrophages, and are important for the recognition of fungal pathogens. ${ }^{46,48,50,51}$ Recognition of fungi by Dectin-1 on macrophages leads to 


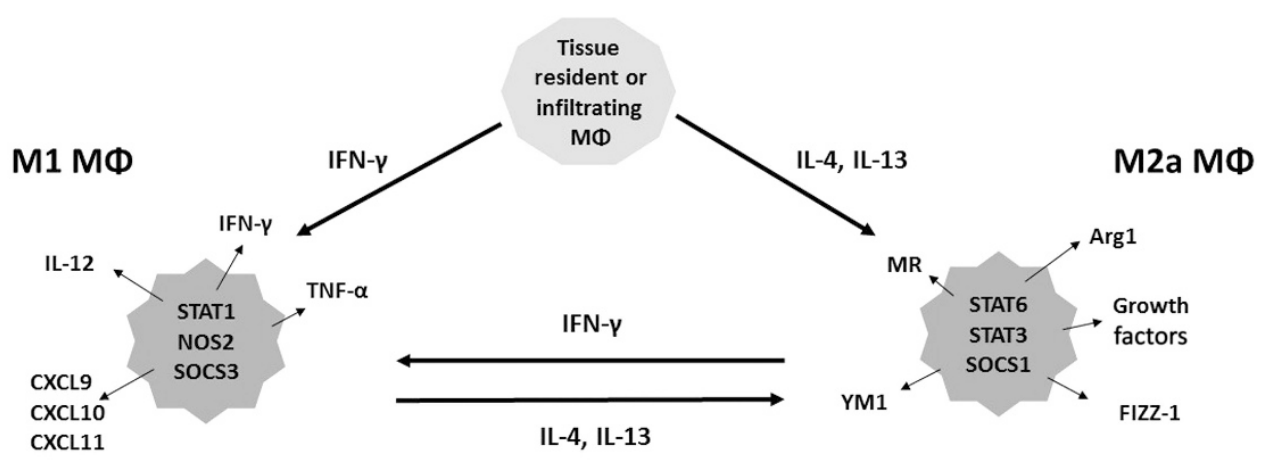

Protective against:

Cryptococcus neoformans

Candida albicans

Paracoccidioides brasiliensis

Coccidioides immitis

Histoplasma capsulatum

Aspergillus fumigatus

Implicated in protection against:

Pneumocystis spp.

Induced by:

Cryptococcus neoformans but does

not contribute to clearance

Figure 1 Predominant macrophage activation during pulmonary fungal infections includes M1 and M2a phenotypes. M1 macrophages arise in the presence of interferon (IFN)- $\gamma$ produced by Thelper type 1 (Th1)-type T cells, natural killer cells and activated antigen-presenting cells (not shown). These macrophages are generally microbicidal via the production of reactive oxygen and nitrogen species and promote the generation of a Th1-type immune response. M2a macrophages arise in the presence of cytokines interleukin (IL)-4 and/or IL-13 and are generally not efficient killers of invading pathogens. Instead, M2a macrophages produce growth factors and components of the extracellular matrix and promote the generation/maintenance of Th2-type immune responses. Macrophages have a unique plasticity as polarized macrophages are capable of changing their functional phenotype as the cytokine microenvironment changes. Arg1, arginase 1; CXCL, C-X-C motif chemokine ligand; FIZZ-1, found in inflammatory zone 1; MR, mannose receptor; NOS2, nitric oxide synthase 2; SOCS, suppressor of cytokine signaling; STAT, signal transducer and activator of transcription; TNF, tumor necrosis factor.

Dectin-1-dependent ROS production, ${ }^{46}$ and Dectin-2 is linked to the promotion of protective Th17 cytokine responses against Candida. $^{50,52}$ (The complex roles of Th17 immunity and Dectin-1/Dectin-2 have been reviewed elsewhere. ${ }^{14,53-59}$ )

During the damage response, anti-inflammatory cytokines, including IL-4 and IL-13, increase, and this increase induces the polarization of macrophages toward an M2 phenotype (Figure 1). ${ }^{15,58,60} \mathrm{M} 2$ macrophages contribute to the suppression/regulation of inflammatory responses and have a pivotal role in wound healing. ${ }^{15,37,40,58} \mathrm{M} 2$ macrophages have been further subcategorized into three functional categories. ${ }^{15,16}$ Macrophages activated by IL- 4 or IL-13 are termed M2a macrophages, which secrete components of the extracellular matrix that are important for wound healing; exposure to immune complexes and IL-1R or TLR agonists induces M2b macrophages, which exert immune-regulatory functions and, along with M2a macrophages, drive Th2-type responses; and M2c macrophages are induced by IL-10 and glucocorticoid hormones and have roles in immune-regulation and tissue remodeling. ${ }^{15,16}$ A recent review by Martinez and Gordon ${ }^{61}$ proposes that macrophages do not form stable subsets but instead respond to a combination of factors present in tissues where different cellular pathways interact forming complex phenotypes. Thus, the traditional M1/M2 paradigm needs to be reassessed to better understand the complexities of macrophage activation. The current review focuses on M1 macrophages and M2a macrophages, both of which are associated with antifungal responses ${ }^{6,62}$ (Figure 1). IL-4 and IL-13 are secreted by immune cells, such as Th2-type $\mathrm{CD}^{+} \mathrm{T}$ cells, basophils, eosinophils, and mast cells. ${ }^{37,40}$ These cytokines can affect macrophages by inhibiting autophagy, hampering NO production, increasing arginase activity, and deterring macrophagemediated pathogen killing. ${ }^{37}$ Other sources of IL-13 include the group 2 innate lymphoid cells (ILCs; ILC2s), which aid in the promotion of Th2-type immune responses. ${ }^{63,64}$ Recent studies showed that exposure of epithelial cells to chitin, an integral part of the cell wall of numerous fungi, led to the production of IL-25, IL-33, and thymic stromal lymphopoietin. ${ }^{65}$ In response to these cytokines, ILC2s expressed IL-5 and IL-13 resulting in increased eosinophil and M2a macrophages. ${ }^{65}$ Chitin also triggers IL-4 expression by innate immune cells such as eosinophils and basophils, leading to induction of M2 macrophages. ${ }^{65,66}$ Stimulation with IL-4 induces the expression of mediators used for tissue remodeling, fibroblast accumulation, and collagen deposition-components which are important for wound healing, but do not generally assist in antimicrobial activities. ${ }^{15,16,37,40}$ The expression of IL-4 results in increased expression of mannose receptor (MR or CD206), the first described M2 macrophage activation-associated marker. ${ }^{67}$ Historically, the general markers of M2 macrophage activation include arginase1 (Arg1), found in inflammatory zone 1 (FIZZ1 , also known as resistin-like $\alpha$ or Relm- $\alpha$ ), and chitinase and chitinase-like molecules, such as YM1 (Chi313) and YM2. ${ }^{15,40}$ Arg1 has a role in the production of polyamines and prolines, which control cell proliferation and collagen production, respectively, thus indicating the essential role of M2 macrophages 
in tissue remodeling and wound healing. ${ }^{68,69}$ FIZZ-1 is not only expressed by $\mathrm{M} 2$ macrophages but is also highly induced in type II alveolar epithelial cells when stimulated by Th2-associated cytokines IL-4 and IL-13, and it is associated with the pathogenesis of lung fibrosis. ${ }^{70}$ Therefore, when evaluating FIZZ-1 and the expression of other M2 macrophage markers in vivo, it is critical to identify the source. Chitinase-like molecules YM1 and YM2 are produced in murine lungs during Th2-type immune responses and are commonly observed as crystals at the site of parasitic and fungal infections. ${ }^{71}$ Their role is not clearly understood; however, in vitro assays have revealed that YM1 and YM2 are chemotactic for eosinophils, T lymphocytes, and polymorphonuclear leukocytes. ${ }^{72}$ Additional markers of M2 macrophage activation include tissue remodeling and immunoregulatory genes, such as matrix metalloproteinases 2 and 7, and adenosine A3 receptor. ${ }^{73}$ Interestingly, during $C$. neoformans central nervous system infection, monocyte-derived macrophages, but not microglia, exhibit the M2 markers MR and YM1. ${ }^{74}$

Macrophages have a unique plasticity that allows them to alter their phenotype depending on the cytokine microenvironment. ${ }^{75-77}$ When polarized toward an M1 phenotype in the presence of IFN- $\gamma$, macrophages can re-polarize to an M2 phenotype when stimulated with IL-4. Similarly, M2-polarized macrophages can re-polarize toward a functional M1 phenotype in the presence of IFN- $\gamma,{ }^{75,77,78}$ signifying the critical importance of the local cytokine milieu in driving macrophage polarization. IL- 4 and IFN- $\gamma$ have been shown to cross-regulate each other as conditions conducive to IFN- $\gamma$ production inhibit IL-4 production. ${ }^{79}$ IFN- $\gamma$ production by Th1-type T cells and NK cells can stimulate M1 macrophage activation in a signal transducer and activator of transcription (STAT) 1-dependent manner. ${ }^{80}$ IL-4 and/or IL-13 induces M2 macrophage activation by stimulating the STAT6 pathway. ${ }^{65,70,81-83}$ One of the most commonly used markers for M2 macrophage activation, Arg1, is considered a context-dependent marker as it can be induced by STAT6 as well as STAT3, which has been associated with regulating M2 macrophage polarization. ${ }^{84-86}$ Arg1 competes with iNOS for the substrate L-arginine and produces $\mathrm{L}$-ornithine and urea while iNOS and L-arginine yield NO and citrulline. ${ }^{87}$ The Arg1-to-iNOS ratio is often considered an indicator of macrophage polarization phenotype; however, the regulatory network in vivo has proven to be quite complex. ${ }^{58}$ Depletion of L-arginine in peritoneal-derived macrophages pretreated with IL-4 in vitro prevents the enzymatic activity of iNOS to produce NO; however, this inhibition of NO production can be overcome by adding supplementary L-arginine. ${ }^{88,89}$ Therefore, conditions conducive to the induction of alternatively activated macrophages can inhibit classical macrophage activation..$^{90}$

Fungal pathogens, such as C. neoformans, ${ }^{7,74,91-93}$ H. capsulatum, ${ }^{94}$ P. brasiliensis, ${ }^{95,96}$ Coccidioides immitis, ${ }^{97}$ C. albicans, ${ }^{98}$ and $B$. dermatitidis, ${ }^{99}$ are sensitive to the NO produced by M1 macrophages. However, many fungi use various mechanisms to avoid being killed by $\mathrm{NO} \cdot{ }^{100,101}$ In the case of $H$. capsulatum, macrophages can efficiently phagocytize the fungus but are unable to kill it until activated by cytokines produced by activated T cells. ${ }^{102,103} \mathrm{P}$. brasiliensis is capable of inhibiting macrophage NO production by an unknown mechanism, resulting in deficient killing of the fungus. ${ }^{99,104,105}$ $B$. dermatitidis is believed to directly inhibit the enzyme iNOS, thus preventing NO production by macrophages. ${ }^{99}$ Coccidioides has the ability to suppress NO production; however, NO does not seem to be required for clearance, indicating that there is another mechanism important for host defense. ${ }^{106,107}$ C. albicans and C. neoformans are also thought to mediate NO suppression by downregulation of macrophage iNOS RNA. ${ }^{108,109}$ In C. albicans, deletion of the gene CaYHB1 results in decreased virulence due to NO sensitivity, nevertheless, mice still succumb to systemic infection, ${ }^{98}$ indicating that killing by RNS may not be critical to protection against systemic C. albicans infections. Conversely, inhibition of iNOS by $C$. neoformans results in M2 macrophage activation and progression of disease, ${ }^{7,110-113}$ thus, avoiding M1 macrophage activation altogether. Pneumocystis can inhibit functional NO by preventing iNOS from forming a homodimer that is required for NO production. ${ }^{114,115}$ In contrast to other fungal pathogens, Pneumocystis can be cleared by the activation of M2 macrophages. ${ }^{62,114}$ The subsequent sections of this review focus on macrophage polarization during fungal infections, principally C. neoformans and Pneumocystis species, as the majority of research in this area has been done with these prototypical model yeasts.

\section{"CLASSICAL" WARRIORS IN HOST DEFENSE}

A number of fungal respiratory pathogens enter the host via inhalation of the infectious propagule from the environment into the lung alveoli. Here the organisms are capable of proliferation and often disseminate to other organs, particularly when the host's immune system is incapable of curtailing the infection. C. neoformans is a model organism for the study of protective M1 macrophages and associated Th1-type immune responses that aid in resolution of disease. C. neoformans has been traditionally viewed as an opportunistic pathogen that causes disease predominantly in immunocompromised individuals, such as AIDS patients. ${ }^{116,117}$ C. neoformans is generally inhaled by the host and, in healthy individuals, the yeast can be cleared. Conversely, in immunocompromised individuals and in some otherwise healthy individuals with no discernable underlying condition, the cryptococci can disseminate to the central nervous system, resulting in potentially fatal meningoencephalitis. Alveolar macrophages are generally one of the first cell types to encounter C. neoformans, and the interactions between these immune cells and the yeast can determine the outcome of the infection. ${ }^{118,119}$

Protection against C. neoformans is largely mediated by Th1-type cell-mediated immune responses which are characterized by cytokines including IFN- $\gamma$, TNF- $\alpha$, IL- 2 , and IL-12. ${ }^{91,110,120-126}$ These conditions promote M1 macrophage activation and production of $\mathrm{NO}$ and other antimicrobial factors. Yet, infection with C. neoformans, including the highly virulent strain H99, results in Th2-type-polarized cytokine 
responses; production of IL-4, IL-5, and IL-13; and M2 macrophage activation..$^{91,92,112,127-129}$ These macrophages are able to easily phagocytize the cryptococci but are not efficient killers of the yeast. ${ }^{6,7,111,130}$ C. neoformans cells can survive within M2 macrophages and use them as a protective niche to evade recognition and killing by the host. ${ }^{131}$ To illustrate, IFN$\gamma^{-/-}$mice given an experimental pulmonary infection with C. neoformans have a propensity to gravitate towards an M2 phenotype and generate a Th2-type cytokine environment within the lungs, correlating with increased intracellular fungal growth within macrophages and more severe pulmonary infection (Table 1). ${ }^{110,111}$ Conversely, when infected with C. neoformans, IL-4 ${ }^{-1-}$ mice have a reduced fungal burden within host macrophages and a decrease in markers for M2 activation. ${ }^{111}$ Furthermore, mice with macrophage-specific ablation of IL- $4 \mathrm{R} \alpha$ have a significantly increased survival rate and decreased pulmonary fungal burden as compared with that of wild-type (WT) mice. ${ }^{132}$ These conditional knockout (KO) mice also have an increase in iNOS and a decrease in Arg1, YM1, and MR in pulmonary tissue as compared with what occurs with WT mice. ${ }^{132}$ This further demonstrates the role of IL-4 in inhibition of M1 macrophage-polarizing conditions during C. neoformans infection. Experimental pulmonary infection with $C$. neoformans strain $52 \mathrm{D}$ results in a chronic infection in $\mathrm{C} 57 \mathrm{BL} / 6$ mice, but the infection is eventually resolved in $\mathrm{BALB} / \mathrm{c}$ mice. ${ }^{11,133}$ Inoculation with $C$. neoformans strain 52D in the chronic model with $\mathrm{C} 57 \mathrm{BL} / 6$ mice results in a dynamic shift from Th2- to Th1-type cytokine production at 5 weeks after inoculation. This shift surprisingly does not aid in fungal clearance, suggesting that the initial Th2-type cytokine response allows for the establishment of a chronic fungal infection, which is not overcome by subsequent increases in IFN- $\gamma$ and TNF- $\alpha .{ }^{111}$ Additionally, deletion of the M2-polarizing cytokine IL-13 results in decreased expression of M2 macrophage activation markers, less lung eosinophilia, reduced production of Th2-type polarizing cytokines, and increased survival as compared with infected WT mice and IL-13overexpressing transgenic mice (Table 1). ${ }^{91}$ Taken together, both IL-4 and IL-13 facilitate M2 macrophage polarization during infection with $C$. neoformans, resulting in a defective anti-cryptococcal immune response.

The role of TLRs in cryptococcal infection is controversial as studies have demonstrated conflicting data regarding the necessity of TLRs, such as TLR2 and TLR4. TLR2 recognizes a wide range of bacterial, fungal, and viral pathogen-associated molecular patterns, including lipopeptides, peptidoglycan, zymosan, and hemagglutinin. ${ }^{34}$ TLR4 primarily recognizes bacterial lipopolysaccharide, fungal o-linked mannans, and glucuronoxylomannan. ${ }^{134}$ Both of these TLRs signal through the TIR (Toll/IL-1 receptor) domain-containing adaptor molecule MyD88 (myeloid differentiation primary response gene 88)-dependent pathway, which drives the induction of inflammatory cytokines. ${ }^{34}$ Macrophages with deficient TLR2 expression or MyD88 ablation exhibit reduced production of TNF- $\alpha$ when cultured with $C$. neoformans in vitro. ${ }^{135}$ Furthermore, $\mathrm{TLR}^{-/-}$and MyD88 $8^{-/-}$mice show a decreased expression of TNF- $\alpha$, IFN- $\gamma$, and IL-12p40 transcripts in the lungs, brain, and spleen during infection with $C$. neoformans, a result which may indicate that the TLR2/MyD88 pathway is important for host defense against $C$. neoformans infection. ${ }^{135}$ The lack of production of these Th1-type cytokines, particularly IFN- $\gamma$, could suggest a defect in M1 macrophage activation, which may explain their increased susceptibility to cryptococcal infection. Other studies have shown that these receptors may not be required or are only marginally helpful for overcoming C. neoformans infection. ${ }^{136,137}$ However, the consensus is that the TLR-associated adaptor protein MyD88 is important for protection not only against $C$. neoformans but also against other fungal pathogens. ${ }^{47,135,137,138}$ Another receptor, TLR9, has recently been implicated in M1 macrophage activation and protection in BALB/c mice inoculated with $C$. neoformans strain 52D. ${ }^{130}$ TLR9 is found on the endosomal membrane within host immune cells, including dendritic cells (DCs), plasmacytoid DCs (pDCs), monocytes, and macrophages in mice and $\mathrm{pDCs}$ and $\mathrm{B}$ cells in humans. This receptor recognizes unmethylated pathogen CpG DNA following its ingestion and degradation by the phagocyte. ${ }^{139,140}$ TLR9 specifically interacts with cryptococcal CpG DNA in DCs, resulting in the secretion of IL-12p40 and the expression of co-stimulatory molecule CD40. ${ }^{141}$ Cryptococcal infection in mice with TLR9 deletion leads to decreased production of M1-polarizing IFN- $\gamma$ and TNF- $\alpha$ compared with WT mice. Additionally, TLR9 ${ }^{-/}$mice produce more of the M2-polarizing cytokine IL-4, a condition that correlates with decreased infiltration of leukocytes into the lungs and ultimately survival (Table 1). ${ }^{130}$ More compelling is that TLR9 $^{-1-}$ mice have increased gene expression of M2 markers Arg1 and FIZZ-1 and decreased expression of iNOS at 3 weeks post-infection, ${ }^{130}$ suggesting that cryptococcal degradation and recognition of the CpG DNA by TLR9 is necessary for protection against C. neoformans. On the contrary, scavenger receptor A (SRA or CD204) is a receptor on immune cells, including macrophages, that senses a broad range of ligands expressed by C. neoformans, ${ }^{142-144}$ including heat-shock proteins. ${ }^{145}$ However, SRA has not been implicated in the activation of macrophages in response to the yeast. ${ }^{146}$ Deletion of SRA in mice leads to decreased production of Th2-type, M2 macrophage-associated cytokines IL-4 and IL-13 by pulmonary leukocytes. ${ }^{147}$ Additionally, following inoculation with $C$. neoformans, $\mathrm{SRA}^{-1-}$ mice have an increase in iNOS transcripts and a decrease in Arg1 transcripts within pulmonary macrophages; however, lack of SRA expression is not sufficient for macrophage fungicidal activity. ${ }^{147}$

As infection with virulent $C$. neoformans strains elicit a nonprotective, Th2-type immune response, a need remained for an infection model that allowed for the study of protective anticryptococcal immune responses. Consequently, the highly virulent $C$. neoformans strain $\mathrm{H} 99$ was genetically engineered to express murine IFN- $\gamma$ and was designated H99 $\gamma .{ }^{148}$ This modified strain elicits protective immune responses in $\mathrm{BALB} / \mathrm{c}$, $\mathrm{A} / \mathrm{Jcr},{ }^{7,148,149}$ and C129 mice (unpublished data), thus providing a model for characterizing protective immune responses against Cryptococcus (Table 1). Furthermore, immunization 

progression

\begin{tabular}{|c|c|c|}
\hline Modification/treatment & $\begin{array}{l}\text { M } \Phi \text { Effect on disease progression } \\
\text { polarization }\end{array}$ & References \\
\hline
\end{tabular}

Cryptococcus

IFN- $\gamma^{-/-}$

$\mathrm{IL}-4^{-1-}$

M2

MФ-specific IL-4R ${ }^{-/-}$

$\mathrm{TLR9}^{-/-}$

H99 infection

M1

H99 immunization +

C. neoformans $\mathrm{H} 99$

$\mathrm{T} 1 / \mathrm{ST}^{-/-}(\mathrm{IL}-33 \mathrm{R})$

$\mathrm{IL}-13^{-/-}$

M1

Scavenger receptor $\mathrm{A}^{-/-}$

M1?

Mannose receptor $^{-1-}$

Unknown

Pneumocystis

Src TKO

Recombinant IL-33

Caspase 9 inhibition

Mannose receptor ${ }^{-1-}$

STAT4 $^{-/-}$(C57BL/6 mice) $\quad \uparrow M 2$

$\mathrm{STAT4}^{-/-}$(BALB/C mice) $\quad \downarrow$ M2

Sulfasalazine

\section{Aspergillus \\ TLR9 $^{-1-}$}

Serum amyloid $\mathrm{P}$

\section{Histoplasma}

Histone 2B antibody

$\mathrm{SOD}^{-1-}$
M2

Unknown

$\downarrow \mathrm{M} 2$

Unknown

M2

M2

Unknown

Unknown

Unknown
Th2-type immune response, increased intracellular growth within $M \Phi$, decreased transcripts for CXCL9 and CXCL10 and increased expression of CCL22

Decreased intracellular growth, increased transcripts for CXCL9 and CXCL10, decreased gene expression for CCL22

Increased survival, decreased pulmonary fungal burden

Decreased pulmonary leukocyte infiltration, decreased survival, defects in granuloma formation, increased intracellular yeasts, defects in Th polarization

Th1-type immune response, increased pulmonary leukocyte infiltration, decrease in pulmonary fungal burden, increased survival

Th1-type immune response, increased pulmonary leukocyte infiltration, decrease in pulmonary fungal burden, increased survival, increased STAT1 phosphorylation

Decreased fungal burden, decreased dissemination, increased survival, decreased eosinophilia, diminished goblet cell hyperplasia and mucus hyper-secretion, decreased serum lgE

Decrease in Th2-polarizing cytokines, decreased serum IgE, decreased mucus production, decreased eosinophilia

Decrease in Th2-type cytokine production, increased iNOS transcripts and decreased Arg1 transcripts in pulmonary $\mathrm{M} \Phi$, not sufficient for fungicidal activity

Defects in adaptive immune response, increased susceptibility

111

111

132

130

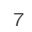

6

179

91

147

193

173

Increased inflammatory cell recruitment, increased cytokine (including IL-33)

and chemokine production, increased $М \Phi$ killing of the yeast

Reduction in pulmonary fungal burden, increased CCL17 production

62

163 inflammation, increased survival

Increased pulmonary phagocyte recruitment, increased pathology, accumulation of glycoproteins, equal susceptibility to WT mice

No difference in fungal burden compared with WT, initial decrease in Th1- and Th2-type cytokine production, increased CCL17 production, elevated PC-specific antibody levels, increased Th2-type cytokines in draining lymph nodes

Increased fungal burden compared with WT, prolonged decrease in Th1- and Th2-type cytokine production, decreased CCL17 production, impaired Th2-type cytokines in draining lymph nodes

Reduced disease severity, reduced inflammation, increased $\mathrm{M} \Phi$ phagocytosis, promotion of Th2-type immune response

172

182

182

164

138

Th2-type immune response, decreased organ fungal burden

192 allergic airway disease
194,195

fungal burden, increased survival

Increased susceptibility of $H$. capsulatum to PMN and M1-produced ROS,

decreased virulence, increased survival of the host

$\downarrow$, decrease in macrophage activation markers; $\uparrow$, increase in macrophage activation markers:? evidence suggests M1 activation but is inconclusive; Arg1 arginase-1; CCL17, chemokine ligand 17; CXCL, C-X-C motif chemokine ligand; H99 , IFN- $\gamma$-producing Cryptococcus neoformans strain; IFN- $\gamma$ interferon-gamma; IgE, immunoglobulin E; IL, interleukin; IL-4R, IL-4 receptor; iNOS, inducible nitric oxide synthase; M1, classically activated macrophage; M2 alternatively activated macrophage; M $\Phi$, macrophage; PC, Pneumocystis; PMN, polymorphonuclear leukocyte; ROS, reactive oxygen species; SOD3, superoxide dismutase 3; Src TKO, Src-family tyrosine kinase triple knockout; STAT, signal transducer and activator of transcription; T1/ST2, unique IL-33 receptor; Th2, T helper type 2; TLR9, Toll-like receptor 9; WT, wild type. 
with $\mathrm{H} 99 \gamma$ affords $100 \%$ protection against subsequent challenge with WT C. neoformans H99. ${ }^{6,148}$ In both primary infection with $\mathrm{H} 99 \gamma$ and secondary C. neoformans $\mathrm{H} 99$ challenge of mice immunized with $\mathrm{H} 99 \gamma$, there is a decrease in fungal burden, an increase in survival, and an increase in M1 macrophage activation as compared with mice given a primary inoculation with the C. neoformans $\mathrm{H} 99$ or a pulmonary challenge with C. neoformans $\mathrm{H} 99$ following mock immunization with heatkilled C. neoformans H99 (HKC.n.). ${ }^{6,7,148}$ Pulmonary macrophages from mice immunized with $\mathrm{H} 99 \gamma$ (protected) and challenged with $C$. neoformans $\mathrm{H} 99$ have an increase in iNOS transcripts, an increase in NO production, and a decrease in transcripts for Arg1, YM1, FIZZ-1, and MR as compared with mice immunized with HKC.n (non-protected). ${ }^{6}$ In addition, studies have indicated that the M1 macrophages induced by the IFN- $\gamma$-producing C. neoformans strain are likely activated via STAT1 signal transduction pathways, as total STAT1 and phosphorylated STAT1 protein, along with transcripts for STAT1-regulated genes, are increased in macrophages from protectively immunized mice. ${ }^{6}$ These findings suggest that the induction of M1 macrophages, which are associated with protective immune responses to C. neoformans, is STAT1 mediated. Thus stimulation of the STAT1 pathway could provide a novel approach to anti-cryptococcal immune therapies and may be important for other fungal infections where M1 macrophages are protective.

\section{THE "ALTERNATIVE” IN HOST RESPONSES}

Like C. neoformans, Pneumocystis jiroveci (formerly known as Pneumocystis carinii, which is currently the name of the Pneumocystis species used in rats while $P$. murina is the species used in mice) is an opportunistic fungal pathogen most commonly associated with AIDS patients. ${ }^{150,151}$ Infection with $P$. jiroveci in immunocompromised individuals can result in life-threatening pneumonia. Fortunately, the incidence of Pneumocystis pneumonia (PCP) among AIDS patients has decreased with the introduction of highly active antiretroviral therapy ${ }^{152}$; nevertheless, PCP remains a concern. The mortality rate for AIDS patients at medical facilities during two retrospective studies was approximately $10-11 \%$ and is as high as $29 \%$ in one study when intensive care was required. ${ }^{153,154}$

The role of T cells is a debated topic. Studies have shown that $\mathrm{CD}^{+} \mathrm{T}$ cells have a critical role in host defense against Pneumocystis, because depletion of $\mathrm{CD} 4^{+} \mathrm{T}$ cells increases the susceptibility to PCP. ${ }^{155-157}$ However, contradictory studies suggest that resolution of an infection with Pneumocystis can occur despite persistent $\mathrm{CD} 4{ }^{+}$lymphocyte depletion ${ }^{158,159}$; therefore, it may be inferred that other immune cells, such as macrophages, are essential for resolving PCP. Studies suggest that alveolar macrophages contribute to an effective antiPneumocystis host response ${ }^{10,160-163}$ and serve as the downstream effector cell for $\mathrm{CD} 4{ }^{+} \mathrm{T}$ cell-dependent clearance, ${ }^{164}$ although much of the evidence is circumstantial. Enhanced Pneumocystis pathogenesis is associated with a reduction in alveolar macrophage numbers, ${ }^{165}$ an effect which may be due to apoptosis induced by the organism. ${ }^{166}$ Reduction of macrophage apoptosis in rats and mice via inhibition of caspase 9 during infection with Pneumocystis is associated with decreased pulmonary fungal burden, increased phagocytosis, and host survival. ${ }^{163}$ The improvement of disease resolution when macrophage apoptosis is prevented indicates that the presence of pulmonary macrophages and, therefore, prevention of apoptosis is critical to host defense.

The M2 macrophage phenotype is associated with the C-type lectin receptor MR, which recognizes the carbohydrate group mannose, a structural component of fungal cell walls. ${ }^{167} \mathrm{MR}$ has been implicated in the mediation of cytokine production, including IL- 6 , TNF- $\alpha$, MCP-1, GM-CSF, IL- $1 \beta$, IL- 12 , and IL-10, and is capable of recognizing numerous fungi, including C. neoformans, C. albicans, and P. jiroveci. ${ }^{167}$ Human alveolar macrophages recognize opsonized Pneumocystis organisms largely via $M R$, resulting in binding and phagocytosis of the fungus. ${ }^{168,169} \mathrm{MR}$ is also found on various other cell types, including DCs and, though less abundantly, M1 macrophages. In the murine model of PCP, induction of IL-1 $\beta$, IL- 6 , and TNF- $\alpha$ transcripts, as well as an influx of alveolar macrophages, is associated with clearance of the organism. ${ }^{170}$ Use of an MR-blocking ligand or siRNA silencing of MR in human macrophages in vitro promotes the release of TNF- $\alpha$ to unopsonized $P$. jiroveci, which is not released under WT conditions in response to the unopsonized fungus. ${ }^{171} \mathrm{MR} \mathrm{KO}$ mice infected with Pneumocystis were no more susceptible to PCP than WT mice. ${ }^{172}$ However, MR KO mice exhibited a greater influx of phagocytes into the lung alveoli during infection, and this increase in pulmonary infiltrates was accompanied by greater pathology, including accumulation of glycoproteins which are normally cleared by cells expressing MR (Table 1). ${ }^{172}$ Taken together, $\mathrm{MR}^{+}$macrophages recognize Pneumocystis and may aid in regulation of pro-inflammatory TNF- $\alpha$ and subsequent phagocyte infiltration to the lungs, thus preventing deleterious inflammatory responses during Pneumocystis infection.

Recognition of $P$. murina by alveolar macrophages leads to activation of Src-family tyrosine kinases (SFKs). Recently, a study by Nelson et al. ${ }^{173}$ showed that mice deficient in the SFKs Hck, Fgr, and Lyn (termed Src triple knockout or Src TKO mice) demonstrate augmented clearance of $P$. murina in the mouse model of PCP (Table 1). However, Src TKO mice had increased cytokine and chemokine levels, as well as increased inflammatory cell recruitment to the lungs. ${ }^{173}$ In addition, the alveolar macrophages of Src TKO mice more efficiently killed $P$. murina as compared with macrophages from infected WT mice. ${ }^{173}$ Further study of PCP in the Src TKO mice revealed that clearance of Pneumocystis is associated with enhanced M2a macrophage activation, as evidenced by increased levels of FIZZ-1, Arg1, and YM1 transcripts in the lungs at day 3 postinfection as compared with what occurred with WT mice. ${ }^{62}$ In addition, while there was no increase in IL-4 and IL-13, there was an increase in IL-33, ${ }^{62}$ which can work synergistically with IL-4 and IL-13, ${ }^{174}$ thus suggesting that IL-33 may have a role in enhancing M2a macrophage activation during Pneumocystis infection. Other studies have indicated that IL-33 may have a 
role in amplifying the polarization of M2 macrophages and potentially contributes to airway inflammation. ${ }^{175}$ Activated NK T cells are capable of inducing alveolar macrophages to produce IL-33, further activating NK T cells, as well as ILCs, to produce IL-13. ${ }^{176}$ Intranasal administration of chitin in mice resulted in the increased expression of IL-25, IL-33, and thymic stromal lymphopoietin, resulting in the production of IL-5 and IL-13 by ILC2s as well as M2 macrophage activation. ${ }^{65}$ The study also showed that chitin stimulation resulted in ILC2-mediated suppression of Th1- and Th17-type cytokine responses and increased eosinophil infiltration, further demonstrating a link between IL-33 and the cytokine microenvironment in the lung during fungal-induced inflammation. ${ }^{65} \mathrm{In}$ humans, chemoattractant receptor $\mathrm{CRTH} 2{ }^{+}$ILCs were shown to respond to IL-33 and IL-25 (IL-17E) by the production of IL-13. ${ }^{177}$ Pretreatment of macrophages with recombinant IL-33 (rIL-33) and IL-13 enhanced in vitro killing of $P$. murina as compared with macrophages pretreated with IL-13 alone, IL-33 alone, IFN- $\gamma$ alone, or untreated macrophages. ${ }^{62}$ Furthermore, intraperitoneal injections of rIL-33 in mice during infection led to a reduction in pulmonary fungal burden and to increases in markers of M2a activated macrophages and their by-products, such as CCL17/thymus and activation-regulated chemokine that can lead to recruitment of Th2-type T cells (Table 1). ${ }^{16,62,178}$ Alternatively, IL-33 signaling has been shown to have a detrimental role during infection with $C$. neoformans and is upregulated during infection with the yeast. ${ }^{179}$ Deficiency in T1/ST2, the unique IL-33R, resulted in reduced M2 activation and decreased fungal burden and dissemination of $C$. neoformans. The results of these studies further exemplify how infection with different fungal organisms requires variations in the host's immune response to prevent the progression of disease.

An important point to remember is that not all mouse strains produce the same results during experimental infections. A recent study examined the role of STAT4 during the protective immune response against pulmonary infection with Pneumocystis using both C57BL/6 and BALB/c mice with STAT4 deletion (Table 1). STAT4 is activated by IL-12 signaling which, along with the transcription factor T-bet, is required for optimal development of Th1-type $\mathrm{T}$ cells. ${ }^{180}$ STAT4 has also been shown to antagonize Th2 development. ${ }^{181}$ C57BL/6 Stat $4^{-1-}$ mice exhibited an increase in transcripts for M2 macrophage activation marker FIZZ-1 while BALB/c Stat $4^{-1-}$ mice had decreased levels of FIZZ-1, and neither group of KO mice showed a difference in mRNA levels for the M1 marker iNOS as compared with WT mice. ${ }^{182}$ Interestingly, $\mathrm{BALB} / \mathrm{c}$ Stat $^{-/-}$mice were more susceptible to PCP, suggesting that the intact M2 macrophage activation in the C57BL/6 Stat $^{-1-}$ mice may contribute to protection. ${ }^{182}$

Overall, evidence suggests that the polarization of alveolar macrophages toward an M2 phenotype is conducive to the induction of protective immune responses against Pneumocystis. Although M2a macrophages appear capable of directly killing Pneumocystis yeasts, it may be that the anti-inflammatory environment promoted by M2a macrophages prevents the development of over-exuberant pulmonary inflammatory responses. In the mouse model of PCP, IL-33 appears to have a role in the protective immune response. Immune cells, such as macrophages and DCs, and alveolar epithelial cells have been implicated as sources of IL-33 mRNA. ${ }^{62,183}$ IL-33, in turn, induces the production of IL-13 by ILCs, ${ }^{176}$ further stimulating M2 macrophages and the progression of a Th2-type immune response. The suppression of inflammatory damage during this response may be an indirect mechanism of protection; however, additional research is necessary.

\section{FUTURE STRATEGIES TO COMBAT FUNGAL PATHOGENESIS}

Many pathogens induce an environment within the host that favors their own proliferation and dissemination. A potential tactic for designing novel treatments is to develop strategies for overcoming these pathogen-mediated effects so as to induce a more microbicidal environment. Therapeutics targeting modifications of the host response rather than the pathogen would limit selective pressure on the microbe that can lead to drug resistance and increased virulence. The studies discussed in this review have indicated that macrophage polarization has a major role in the outcome of infection. Therapeutics targeting macrophage activation to shift polarization toward an antifungal phenotype may provide a novel method for treatment of fungal infections.

In the case of Pneumocystis pneumonia, treatments that reduce pulmonary inflammation and promote the polarization of macrophages toward an M2a phenotype would be beneficial in slowing and/or stopping disease progression. Macrophages treated with IL-33 and IL-13 have an increased fungicidal effect on Pneumocystis compared with M1 macrophages induced by IFN- $\gamma{ }^{62}$ Intraperitoneal injection of rIL-33 in mice led to greater pulmonary clearance of the yeast, ${ }^{62}$ indicating that IL-33 has potential as a novel immunotherapy for PCP. Additionally, sulfasalazine, a potent anti-inflammatory drug, enhances the clearance of Pneumocystis from the lung in the PCP-Immune Reconstitution Inflammatory Syndrome (IRIS) model, correlating with the promotion of M2 macrophage activation. ${ }^{164}$ Sulfasalazine is normally used to treat inflammatory illnesses, such as Crohn's disease ${ }^{184}$ and rheumatoid arthritis, ${ }^{185}$ by altering macrophage and T-cell responses and inhibiting nuclear factor- $\kappa \mathrm{B} .{ }^{186,187}$ During infection with Pneumocystis, sulfasalazine treatment resulted in reduced severity of disease, decreased inflammation, and promotion of M2 macrophage activation. The M2-polarized macrophages displayed enhanced phagocytosis and clearance of the fungus, ${ }^{164}$ further supporting a role of M2 macrophages in protection against PCP.

Skewing of the immune response and subsequent macrophage polarization phenotype is a technique a number of fungal pathogens use to aid in host invasion and colonization. Studies have shown that M2 polarization can be shifted to $\mathrm{M}^{35,188}$; however, it is not known whether the macrophages are being re-polarized or if newly infiltrating macrophages become M1 polarized. Nevertheless, the local cytokine milieu is perhaps the 
final determinant of macrophage polarization phenotype. Studies examining plasticity of tumor-associated macrophages have indicated that administering IFN- $\gamma$ or targeting nuclear factor- $\kappa \mathrm{B}$ have re-polarized M2 macrophages to M1 macrophages in vivo. ${ }^{189,190}$ A recent study has demonstrated that macrophages polarized toward an M2 phenotype with IL-4, as observed during infection with C. neoformans, can be overcome by the addition of IFN- $\gamma$ in vitro, resulting in a phenotypic switch to functional M1 macrophages. ${ }^{78}$ These re-polarized macrophages were fully capable of producing NO and were fungicidal, thus inhibiting proliferation of the yeast. ${ }^{78}$ Therefore, strategies for inducing M1 macrophage activation and/or inhibiting M2 macrophage activation during infection could prove to be a novel and effective method of inducing host protection against Cryptococcus and other fungal infections. For example, treatment of macrophages with kojic acid, a secondary metabolite of fungal species, including Aspergillus and Penicillium, results in increased ROS production but not NO. ${ }^{191}$ More investigation to characterize the macrophage activation phenotype and to determine the anti-fungal activity of kojic acid is needed. Serum amyloid P has recently been shown to inhibit M2 polarization via an Fc $\gamma$ R-dependent mechanism in cultured macrophages. ${ }^{192}$ The effect led to the downregulation of M2 markers, a decrease in STAT6 phosphorylation, and attenuated A. fumigatus-induced allergic airway disease, ${ }^{192}$ suggesting that inhibition of M2 polarization shows promise for treatment of Aspergillus and other pulmonary fungal infections that result in allergic airway disease. Additionally, studies in our lab have suggested that STAT1 has a role in mediating M1 macrophage activation and subsequent protection against C. neoformans ${ }^{6}$; therefore, induction of the IFN- $\gamma /$ STAT1 signaling pathway could provide a potential mechanism for induction of M1 macrophages.

The stimulation of M1 macrophage activation and/or the prevention of M2 macrophage activation have the potential to provide protection against a myriad of fungal infections, including C. neoformans, $H$. capsulatum, and A. fumigatus. Induction of pro-inflammatory responses by M1 macrophages, as well as the production of ROS and RNS, contributes to eradication of the pathogen and resolution of disease. However, induction of M2 macrophages, but not M1 macrophages, is conducive to clearance of Pneumocystis infections. Dampening of pro-inflammatory responses that limit PCP-associated damage, along with the anti-Pneumocystis activity of M2 macrophages, allows the host to resolve the infection. Therefore, discovery and utilization of therapeutics that induce polarization of macrophages toward an anti-fungal phenotype must consider the pathogen in question. Targeting the host's immune response rather than the pathogen could provide a much needed, novel approach to the treatment of fungal infections.

\section{ACKNOWLEDGMENTS}

This work was supported by research grant W911NF-11-1-0136 from the Army Research Office of the Department of Defense and 2RO1 Al071752 from the National Institute of Allergy and Infectious Diseases (NIAID) of the National Institutes of Health (NIH) (to F.L.W. Jr). Thanks to K. Wozniak, A. Cardona, and G. Pizzola for critical reading of the manuscript.

\section{DISCLOSURE}

The authors declared no conflict of interest.

c 2014 Society for Mucosal Immunology

\section{REFERENCES}

1. Park, SJ \& Mehrad, B. Innate immunity to Aspergillus species. Clin. Microbiol. Rev. 22, 535-551 (2009).

2. Powderly, WG. Cryptococcal meningitis and AIDS. Clin. Infect. Dis. 17, 837-842 (1993).

3. Saag, MS et al. Practice guidelines for the management of cryptococcal disease. Infectious Diseases Society of America. Clin. Infect. Dis. 30, 710-718 (2000)

4. van der Horst, $\mathrm{CM}$ et al. Treatment of cryptococcal meningitis associated with the acquired immunodeficiency syndrome. National Institute of Allergy and Infectious Diseases Mycoses Study Group and AIDS Clinical Trials Group. N. Engl. J. Med. 337, 15-21 (1997).

5. Husain, S, Wagener, MM \& Singh, N. Cryptococcus neoformans infection in organ transplant recipients: variables influencing clinical characteristics and outcome. Emerg. Infect. Dis. 7, 375-381 (2001).

6. Hardison, SE, Herrera, G, Young, ML, Hole, CR, Wozniak, KL \& Wormley, FL Jr. Protective immunity against pulmonary cryptococcosis is associated with STAT1-mediated classical macrophage activation. J. Immunol. 189, 4060-4068 (2012).

7. Hardison, SE, Ravi, S, Wozniak, KL, Young, ML, Olszewski, MA \& Wormley, FL Jr. Pulmonary infection with an interferon-gammaproducing Cryptococcus neoformans strain results in classical macrophage activation and protection. Am. J. Pathol. 176, 774-785 (2010).

8. Segal, $\mathrm{BH}$. Role of macrophages in host defense against aspergillosis and strategies for immune augmentation. Oncologist 12, 7-13 (2007).

9. Dubourdeau, $\mathrm{M}$ et al. Aspergillus fumigatus induces innate immune responses in alveolar macrophages through the MAPK pathway independently of TLR2 and TLR4. J. Immunol. 177, 3994-4001 (2006).

10. Limper, AH, Hoyte, JS \& Standing, JE. The role of alveolar macrophages in Pneumocystis carinii degradation and clearance from the lung. J. Clin. Invest. 99, 2110-2117 (1997).

11. Brummer, E, Kethineni, N \& Stevens, DA. Immunological basis for susceptibility and resistance to pulmonary blastomycosis in mouse strains. Cytokine 32, 12-19 (2005).

12. Brummer, E, Hanson, LH \& Stevens, DA. Gamma-interferon activation of macrophages for killing of Paracoccidioides brasiliensis and evidence for nonoxidative mechanisms. Int. J. Immunopharmacol. 10, 945-952 (1988).

13. Brummer, E, Hanson, LH, Restrepo, A \& Stevens, DA. In vivo and in vitro activation of pulmonary macrophages by IFN-gamma for enhanced killing of Paracoccidioides brasiliensis or Blastomyces dermatitidis. J. Immunol. 140, 2786-2789 (1988).

14. Romani, L. Immunity to fungal infections. Nat. Rev. Immunol. 11, 275-288 (2011).

15. Mosser, DM \& Edwards, JP. Exploring the full spectrum of macrophage activation. Nat. Rev. Immunol. 8, 958-969 (2008).

16. Mantovani, A, Sica, A, Sozzani, S, Allavena, P, Vecchi, A \& Locati, M. The chemokine system in diverse forms of macrophage activation and polarization. Trends Immunol. 25, 677-686 (2004).

17. Fels, AO \& Cohn, ZA. The alveolar macrophage. J. Appl. Physiol. 60, 353-369 (1986)

18. Zaynagetdinov, $\mathrm{R}$ et al. Identification of myeloid cell subsets in murine lungs using flow cytometry. Am. J. Respir. Cell Mol. Biol. 49, 180-189 (2013).

19. Hussell, T \& Bell, TJ. Alveolar macrophages: plasticity in a tissue-specific context. Nat. Rev. Immunol. 14, 81-93 (2014).

20. Feng, YH \& Mao, H. Expression and preliminary functional analysis of SiglecF on mouse macrophages. J. Zhejiang Univ. Sci. B 13, 386-394 (2012).

21. Kirby, AC, Coles, MC \& Kaye, PM. Alveolar macrophages transport pathogens to lung draining lymph nodes. J. Immunol. 183, 1983-1989 (2009).

22. Strauss-Ayali, D, Conrad, SM \& Mosser, DM. Monocyte subpopulations and their differentiation patterns during infection. J. Leukoc. Biol. 82, 244-252 (2007) 
23. Shi, C \& Pamer, EG. Monocyte recruitment during infection and inflammation. Nat. Rev. Immunol. 11, 762-774 (2011).

24. Yona, $\mathrm{S}$ et al. Fate mapping reveals origins and dynamics of monocytes and tissue macrophages under homeostasis. Immunity 38, 79-91 (2013).

25. Schulz, $C$ et al. A lineage of myeloid cells independent of Myb and hematopoietic stem cells. Science 336, 86-90 (2012).

26. Hashimoto, $\mathrm{D}$ et al. Tissue-resident macrophages self-maintain locally throughout adult life with minimal contribution from circulating monocytes. Immunity 38, 792-804 (2013).

27. Maus, UA et al. Role of resident alveolar macrophages in leukocyte traffic into the alveolar air space of intact mice. Am. J. Physiol. Lung Cell. Mol. Physiol. 282, L1245-L1252 (2002).

28. Gordon, S \& Taylor, PR. Monocyte and macrophage heterogeneity. Nat. Rev. Immunol. 5, 953-964 (2005).

29. Tsou, CL et al. Critical roles for CCR2 and MCP-3 in monocyte mobilization from bone marrow and recruitment to inflammatory sites. J. Clin. Invest. 117, 902-909 (2007).

30. Serbina, NV \& Pamer, EG. Monocyte emigration from bone marrow during bacterial infection requires signals mediated by chemokine receptor CCR2. Nat. Immunol. 7, 311-317 (2006).

31. Jia, T et al. Additive roles for MCP-1 and MCP-3 in CCR2-mediated recruitment of inflammatory monocytes during Listeria monocytogenes infection. J. Immunol. 180, 6846-6853 (2008).

32. Traynor, TR, Kuziel, WA, Toews, GB \& Huffnagle, GB. CCR2 expression determines $\mathrm{T} 1$ versus $\mathrm{T} 2$ polarization during pulmonary Cryptococcus neoformans infection. J. Immunol. 164, 2021-2027 (2000).

33. Kumagai, $Y \&$ Akira, $S$. Identification and functions of pattern-recognition receptors. J. Allergy Clin. Immunol. 125, 985-992 (2010).

34. Kawai, $T$ \& Akira, $\mathrm{S}$. The role of pattern-recognition receptors in innate immunity: update on Toll-like receptors. Nat. Immunol. 11, 373-384 (2010).

35. Sica, A \& Mantovani, A. Macrophage plasticity and polarization: in vivo veritas. J. Clin. Invest. 122, 787-795 (2012).

36. Stout, RD \& Suttles, J. Functional plasticity of macrophages: reversible adaptation to changing microenvironments. J. Leukoc. Biol. 76, 509-513 (2004).

37. Martinez, FO, Helming, L \& Gordon, S. Alternative activation of macrophages: an immunologic functional perspective. Annu. Rev. Immunol. 27, 451-483 (2009).

38. Kraaij, MD et al. Human monocytes produce interferon-gamma upon stimulation with LPS. Cytokine 67, 7-12 (2014).

39. Choudhry, N, Petry, F, van Rooijen, N \& McDonald, V. A protective role for interleukin 18 in interferon gamma-mediated innate immunity to Cryptosporidium parvum that is independent of natural killer cells. J. Infect. Dis. 206, 117-124 (2012).

40. Murray, PJ \& Wynn, TA. Protective and pathogenic functions of macrophage subsets. Nat. Rev. Immunol. 11, 723-737 (2011).

41. Muller, M, Carter, S, Hofer, MJ \& Campbell, IL. Review: The chemokine receptor CXCR3 and its ligands CXCL9, CXCL10 and CXCL11 in neuroimmunity-a tale of conflict and conundrum. Neuropathol. Appl. Neurobiol. 36, 368-387 (2010).

42. Liu, $Y$ et al. Unique expression of suppressor of cytokine signaling 3 is essential for classical macrophage activation in rodents in vitro and in vivo. J. Immunol. 180, 6270-6278 (2008).

43. Arnold, CE, Whyte, CS, Gordon, P, Barker, RN, Rees, AJ \& Wilson, HM. A critical role for suppressor of cytokine signalling 3 in promoting $M 1$ macrophage activation and function in vitro and in vivo. Immunology 141 , 96-110 (2014).

44. Ding, AH, Nathan, CF \& Stuehr, DJ. Release of reactive nitrogen intermediates and reactive oxygen intermediates from mouse peritoneal macrophages. Comparison of activating cytokines and evidence for independent production. J. Immunol. 141, 2407-2412 (1988).

45. Gantner, BN, Simmons, RM \& Underhill, DM. Dectin-1 mediates macrophage recognition of Candida albicans yeast but not filaments. EMBO J. 24, 1277-1286 (2005).

46. Underhill, DM, Rossnagle, E, Lowell, CA \& Simmons, RM. Dectin-1 activates Syk tyrosine kinase in a dynamic subset of macrophages for reactive oxygen production. Blood 106, 2543-2550 (2005).
47. Viriyakosol, S, Fierer, J, Brown, GD \& Kirkland, TN. Innate immunity to the pathogenic fungus Coccidioides posadasii is dependent on Toll-like receptor 2 and Dectin-1. Infect. Immun. 73, 1553-1560 (2005).

48. Viriyakosol, S, Jimenez Mdel, P, Gurney, MA, Ashbaugh, ME \& Fierer, J. Dectin- 1 is required for resistance to coccidioidomycosis in mice. MBio 4, e00597-00512 (2013).

49. Steele, $\mathrm{C}$ et al. Alveolar macrophage-mediated killing of Pneumocystis carinii f. sp. muris involves molecular recognition by the Dectin-1 betaglucan receptor. J. Exp. Med. 198, 1677-1688 (2003).

50. Saijo, $\mathrm{S}$ et al. Dectin-2 recognition of alpha-mannans and induction of Th17 cell differentiation is essential for host defense against Candida albicans. Immunity 32, 681-691 (2010).

51. McDonald, JU, Rosas, M, Brown, GD, Jones, SA \& Taylor, PR. Differential dependencies of monocytes and neutrophils on dectin-1, dectin-2 and complement for the recognition of fungal particles in inflammation. PLOS One 7, e45781 (2012).

52. Robinson, MJ et al. Dectin-2 is a Syk-coupled pattern recognition receptor crucial for Th17 responses to fungal infection. J. Exp. Med. 206, 2037-2051 (2009).

53. Way, EE, Chen, K \& Kolls, JK. Dysregulation in lung immunity-the protective and pathologic Th17 response in infection. Eur. J. Immunol. 43, 3116-3124 (2013).

54. Korn, T, Bettelli, E, Oukka, M \& Kuchroo, VK. IL-17 and Th17 Cells. Annu. Rev. Immunol. 27, 485-517 (2009).

55. Hardison, SE \& Brown, GD. C-type lectin receptors orchestrate antifungal immunity. Nat. Immunol. 13, 817-822 (2012).

56. Drummond, RA \& Brown, GD. The role of Dectin-1 in the host defence against fungal infections. Curr. Opin. Microbiol. 14, 392-399 (2011).

57. Wuthrich, M, Deepe, GS Jr \& Klein, B. Adaptive immunity to fungi. Annu. Rev. Immunol. 30, 115-148 (2012).

58. Van Dyken, SJ \& Locksley, RM. Interleukin-4- and interleukin-13mediated alternatively activated macrophages: roles in homeostasis and disease. Annu. Rev. Immunol. 31, 317-343 (2013).

59. Gladiator, A \& LeibundGut-Landmann, S. Innate lymphoid cells: new players in IL-17-mediated antifungal immunity. PLoS Pathog. 9, e1003763 (2013).

60. Mantovani, A, Biswas, SK, Galdiero, MR, Sica, A \& Locati, M Macrophage plasticity and polarization in tissue repair and remodelling. J. Pathol. 229, 176-185 (2013).

61. Martinez, FO \& Gordon, S. The M1 and M2 paradigm of macrophage activation: time for reassessment. F1000Prime Rep. 6, 13 (2014).

62. Nelson, MP et al. IL-33 and M2a alveolar macrophages promote lung defense against the atypical fungal pathogen Pneumocystis murina. J. Immunol. 186, 2372-2381 (2011).

63. Walker, JA \& McKenzie, AN. Development and function of group 2 innate lymphoid cells. Curr. Opin. Immunol. 25, 148-155 (2013).

64. Walker, JA, Barlow, JL \& McKenzie, AN. Innate lymphoid cells-how did we miss them?. Nat. Rev. Immunol. 13, 75-87 (2013).

65. Van Dyken, SJ et al. Chitin activates parallel immune modules that direct distinct inflammatory responses via innate lymphoid type 2 and gammadelta T cells. Immunity 40, 414-424 (2014).

66. Reese, TA et al. Chitin induces accumulation in tissue of innate immune cells associated with allergy. Nature 447, 92-96 (2007).

67. Stein, M, Keshav, S, Harris, N \& Gordon, S. Interleukin 4 potently enhances murine macrophage mannose receptor activity: a marker of alternative immunologic macrophage activation. J. Exp. Med. 176, $287-$ 292 (1992).

68. Vercelli, D. Arginase: marker, effector, or candidate gene for asthma?. J. Clin. Invest. 111, 1815-1817 (2003).

69. Meurs, H, Maarsingh, H \& Zaagsma, J. Arginase and asthma: novel insights into nitric oxide homeostasis and airway hyperresponsiveness. Trends Pharmacol. Sci. 24, 450-455 (2003).

70. Liu, T et al. Regulation of found in inflammatory zone 1 expression in bleomycin-induced lung fibrosis: role of IL-4/IL-13 and mediation via STAT-6. J. Immunol. 173, 3425-3431 (2004).

71. Lee, CG et al. Role of chitin and chitinase/chitinase-like proteins in inflammation, tissue remodeling, and injury. Annu. Rev. Physiol. 73, 479-501 (2011)

72. Nio, J, Fujimoto, W, Konno, A, Kon, Y, Owhashi, M \& Iwanaga, T. Cellular expression of murine $\mathrm{Ym} 1$ and $\mathrm{Ym} 2$, chitinase family proteins, as revealed 
by in situ hybridization and immunohistochemistry. Histochem. Cell Biol. 121, 473-482 (2004).

73. Shaykhiev, R et al. Smoking-dependent reprogramming of alveolar macrophage polarization: implication for pathogenesis of chronic obstructive pulmonary disease. J. Immunol. 183, 2867-2883 (2009).

74. Stenzel, $W$ et al. IL-4/L-13-dependent alternative activation of macrophages but not microglial cells is associated with uncontrolled cerebral cryptococcosis. Am. J. Pathol. 174, 486-496 (2009).

75. Gratchev, A et al. Mphi1 and Mphi2 can be re-polarized by Th2 or Th1 cytokines, respectively, and respond to exogenous danger signals. Immunobiology 211, 473-486 (2006).

76. Porcheray, $\mathrm{F}$ et al. Macrophage activation switching: an asset for the resolution of inflammation. Clin. Exp. Immunol. 142, 481-489 (2005).

77. Stout, RD, Jiang, C, Matta, B, Tietzel, I, Watkins, SK \& Suttles, J. Macrophages sequentially change their functional phenotype in response to changes in microenvironmental influences. J. Immunol. 175, 342-349 (2005).

78. Davis, MJ et al. Macrophage M1/M2 polarization dynamically adapts to changes in cytokine microenvironments in Cryptococcus neoformans infection. MBio 4, e00264-00213 (2013).

79. Szabo, SJ, Sullivan, BM, Peng, SL \& Glimcher, LH. Molecular mechanisms regulating Th1 immune responses. Annu. Rev. Immunol. 21, 713-758 (2003).

80. $\mathrm{Hu}, \mathrm{X}$ et al. Sensitization of IFN-gamma Jak-STAT signaling during macrophage activation. Nat. Immunol. 3, 859-866 (2002).

81. Kaplan, MH, Schindler, U, Smiley, ST \& Grusby, MJ. Stat6 is required for mediating responses to IL-4 and for development of Th2 cells. Immunity 4 , 313-319 (1996).

82. Takeda, K, Kishimoto, T \& Akira, S. STAT6: its role in interleukin 4-mediated biological functions. J. Mol. Med. 75, 317-326 (1997).

83. Takeda, $\mathrm{K}$ et al. Essential role of Stat6 in IL-4 signalling. Nature 380 , 627-630 (1996).

84. Qualls, JE et al. Arginine usage in mycobacteria-infected macrophages depends on autocrine-paracrine cytokine signaling. Sci. Signal. 3, ra62 (2010).

85. El Kasmi, KC et al. Toll-like receptor-induced arginase 1 in macrophages thwarts effective immunity against intracellular pathogens. Nat. Immunol. 9, 1399-1406 (2008).

86. Whyte, CS et al. Suppressor of cytokine signaling (SOCS) 1 is a key determinant of differential macrophage activation and function. J. Leukoc. Biol. 90, 845-854 (2011).

87. Bogdan, C, Rollinghoff, M \& Diefenbach, A. Reactive oxygen and reactive nitrogen intermediates in innate and specific immunity. Curr. Opin. Immunol. 12, 64-76 (2000).

88. Modolell, M, Corraliza, IM, Link, F, Soler, G \& Eichmann, K. Reciprocal regulation of the nitric oxide synthase/arginase balance in mouse bone marrow-derived macrophages by $\mathrm{TH} 1$ and $\mathrm{TH} 2$ cytokines. Eur. J. Immunol. 25, 1101-1104 (1995).

89. Rutschman, R, Lang, R, Hesse, M, Ihle, JN, Wynn, TA \& Murray, PJ. Cutting edge: Stat6-dependent substrate depletion regulates nitric oxide production. J. Immunol. 166, 2173-2177 (2001).

90. Takeda, K, Kamanaka, M, Tanaka, T, Kishimoto, T \& Akira, S. Impaired IL-13-mediated functions of macrophages in STAT6-deficient mice. J. Immunol. 157, 3220-3222 (1996).

91. Muller, $U$ et al. IL-13 induces disease-promoting type 2 cytokines, alternatively activated macrophages and allergic inflammation during pulmonary infection of mice with Cryptococcus neoformans. J. Immunol. 179, 5367-5377 (2007).

92. Osterholzer, JJ et al. Cryptococcal urease promotes the accumulation of immature dendritic cells and a non-protective $\mathrm{T} 2 \mathrm{immune}$ response within the lung. Am. J. Pathol. 174, 932-943 (2009).

93. Zhang, $\mathrm{Y}$ et al. Robust Th1 and Th17 immunity supports pulmonary clearance but cannot prevent systemic dissemination of highly virulent Cryptococcus neoformans H99. Am. J. Pathol. 175, 24892500 (2009).

94. Nakamura, LT, Wu-Hsieh, BA \& Howard, DH. Recombinant murine gamma interferon stimulates macrophages of the RAW cell line to inhibit intracellular growth of Histoplasma capsulatum. Infect. Immun. 62, 680-684 (1994).
95. Moreira, AP, Dias-Melicio, LA, Peracoli, MT, Calvi, SA \& Victoriano de Campos Soares, AM Killing of Paracoccidioides brasiliensis yeast cells by IFN-gamma and TNF-alpha activated murine peritoneal macrophages: evidence of $\mathrm{H}(2) \mathrm{O}(2)$ and $\mathrm{NO}$ effector mechanisms. Mycopathologia 166, 17-23 (2008).

96. Livonesi, MC et al. Inducible nitric oxide synthase-deficient mice show exacerbated inflammatory process and high production of both Th1 and Th2 cytokines during paracoccidioidomycosis. Microbes Infect. 11, 123132 (2009).

97. Jimenez Mdel, P, Walls, L \& Fierer, J. High levels of interleukin-10 impair resistance to pulmonary coccidioidomycosis in mice in part through control of nitric oxide synthase 2 expression. Infect. Immun. 74, 3387-3395 (2006).

98. Ullmann, BD et al. Inducible defense mechanism against nitric oxide in Candida albicans. Eukaryot. Cell 3, 715-723 (2004).

99. Rocco, NM, Carmen, JC \& Klein, BS Blastomyces dermatitidis yeast cells inhibit nitric oxide production by alveolar macrophage inducible nitric oxide synthase. Infect. Immun. 79, 2385-2395 (2011).

100. Collette, JR \& Lorenz, MC. Mechanisms of immune evasion in fungal pathogens. Curr. Opin. Microbiol. 14, 668-675 (2011).

101. Seider, K, Heyken, A, Luttich, A, Miramon, P \& Hube, B. Interaction of pathogenic yeasts with phagocytes: survival, persistence and escape. Curr. Opin. Microbiol. 13, 392-400 (2010).

102. Newman, SL. Cell-mediated immunity to Histoplasma capsulatum. Semin Respir. Infect. 16, 102-108 (2001).

103. Newman, SL. Macrophages in host defense against Histoplasma capsulatum. Trends Microbiol. 7, 67-71 (1999).

104. Flavia Popi, AF, Lopes, JD \& Mariano, M. GP43 from Paracoccidioides brasiliensis inhibits macrophage functions. An evasion mechanism of the fungus. Cell. Immunol. 218, 87-94 (2002).

105. Moreira, AP, Dias-Melicio, LA \& Soares, AM. Interleukin-10 but not transforming growth factor beta inhibits murine activated macrophages Paracoccidioides brasiliensis killing: effect on $\mathrm{H}_{2} \mathrm{O}_{2}$ and $\mathrm{NO}$ production. Cell. Immunol. 263, 196-203 (2010).

106. Gonzalez, A, Hung, CY \& Cole, GT. Nitric oxide synthase activity has limited influence on the control of Coccidioides infection in mice. Microb. Pathog. 51, 161-168 (2011).

107. Gonzalez, A, Hung, CY \& Cole, GT. Coccidioides releases a soluble factor that suppresses nitric oxide production by murine primary macrophages. Microb. Pathog. 50, 100-108 (2011).

108. Chinen, T, Qureshi, MH, Koguchi, Y \& Kawakami, K. Candida albicans suppresses nitric oxide (NO) production by interferon-gamma (IFNgamma) and lipopolysaccharide (LPS)-stimulated murine peritoneal macrophages. Clin. Exp. Immunol. 115, 491-497 (1999).

109. Kawakami, K, Zhang, T, Qureshi, MH \& Saito, A. Cryptococcus neoformans inhibits nitric oxide production by murine peritoneal macrophages stimulated with interferon-gamma and lipopolysaccharide. Cell. Immunol. 180, 47-54 (1997).

110. Arora, S, Hernandez, Y, Erb-Downward, JR, McDonald, RA, Toews, GB \& Huffnagle, GB. Role of IFN-gamma in regulating T2 immunity and the development of alternatively activated macrophages during allergic bronchopulmonary mycosis. J. Immunol. 174, 6346-6356 (2005).

111. Arora, S, Olszewski, MA, Tsang, TM, McDonald, RA, Toews, GB \& Huffnagle, GB. Effect of cytokine interplay on macrophage polarization during chronic pulmonary infection with Cryptococcus neoformans. Infect. Immun. 79, 1915-1926 (2011).

112. Xiao, $\mathrm{G}$ et al. Cryptococcus neoformans inhibits nitric oxide synthesis caused by CpG-oligodeoxynucleotide-stimulated macrophages in a fashion independent of capsular polysaccharides. Microbiol. Immunol. 52, 171-179 (2008).

113. Naslund, PK, Miller, WC \& Granger, DL. Cryptococcus neoformans fails to induce nitric oxide synthase in primed murine macrophage-like cells. Infect. Immun. 63, 1298-1304 (1995).

114. Lasbury, ME et al. Defective nitric oxide production by alveolar macrophages during Pneumocystis pneumonia. Am. J. Respir. Cell Mol. Biol. 44, 540-547 (2010).

115. Lee, KS et al. Differential effects of substrate-analogue inhibitors on nitric oxide synthase dimerization. Biochem. Biophys. Res. Commun. 418, 49-55 (2012). 
116. Park, BJ, Wannemuehler, KA, Marston, BJ, Govender, N, Pappas, PG \& Chiller, TM. Estimation of the current global burden of cryptococcal meningitis among persons living with HIV/AIDS. AIDS 23, 525-530 (2009).

117. Antinori, S. New insights into HIV/AIDS-associated cryptococcosis. ISRN AIDS 2013, 471363 (2013).

118. Shao, X, Mednick, A, Alvarez, M, van Rooijen, N, Casadevall, A \& Goldman, DL. An innate immune system cell is a major determinant of species-related susceptibility differences to fungal pneumonia. J. Immunol. 175, 3244-3251 (2005).

119. Zaragoza, O, Alvarez, M, Telzak, A, Rivera, J \& Casadevall, A. The relative susceptibility of mouse strains to pulmonary Cryptococcus neoformans infection is associated with pleiotropic differences in the immune response. Infect. Immun. 75, 2729-2739 (2007).

120. Aguirre, K, Havell, EA, Gibson, GW \& Johnson, LL. Role of tumor necrosis factor and gamma interferon in acquired resistance to Cryptococcus neoformans in the central nervous system of mice. Infect. Immun. 63, 1725-1731 (1995).

121. Collins, HL \& Bancroft, GJ. Cytokine enhancement of complementdependent phagocytosis by macrophages: synergy of tumor necrosis factor-alpha and granulocyte-macrophage colony-stimulating factor for phagocytosis of Cryptococcus neoformans. Eur. J. Immunol. 22 1447-1454 (1992)

122. Flesch, IE, Schwamberger, G \& Kaufmann, SH. Fungicidal activity of IFNgamma-activated macrophages. Extracellular killing of Cryptococcus neoformans. J. Immunol. 142, 3219-3224 (1989).

123. Huffnagle, GB \& Lipscomb, MF. Cells and cytokines in pulmonary cryptococcosis. Res. Immunol. 149, 387-396. discussion 512-384 (1998).

124. Levitz, SM \& DiBenedetto, DJ. Differential stimulation of murine resident peritoneal cells by selectively opsonized encapsulated and acapsular Cryptococcus neoformans. Infect. Immun. 56, 2544-2551 (1988).

125. Kawakami, K, Tohyama, M, Xie, Q \& Saito, A. IL-12 protects mice against pulmonary and disseminated infection caused by Cryptococcus neoformans. Clin. Exp. Immunol 104, 208-214 (1996).

126. Antachopoulos, C \& Walsh, TJ. Immunotherapy of Cryptococcus infections. Clin. Microbiol. Infect. 18, 126-133 (2012).

127. Chen, GH, McNamara, DA, Hernandez, Y, Huffnagle, GB, Toews, GB \& Olszewski, MA. Inheritance of immune polarization patterns is linked to resistance versus susceptibility to Cryptococcus neoformans in a mouse model. Infect. Immun. 76, 2379-2391 (2008).

128. Huffnagle, GB, Boyd, MB, Street, NE \& Lipscomb, MF. IL-5 is required for eosinophil recruitment, crystal deposition, and mononuclear cell recruitment during a pulmonary Cryptococcus neoformans infection in genetically susceptible mice (C57BL/6). J. Immunol. 160, 2393-2400 (1998).

129. Milam, JE, Herring-Palmer, AC, Pandrangi, R, McDonald, RA, Huffnagle, GB \& Toews, GB. Modulation of the pulmonary type 2 T-cell response to Cryptococcus neoformans by intratracheal delivery of a tumor necrosis factor alpha-expressing adenoviral vector. Infect. Immun. 75, 4951-4958 (2007).

130. Zhang, $Y$ et al. TLR9 signaling is required for generation of the adaptive immune protection in Cryptococcus neoformans-infected lungs. Am. J. Pathol. 177, 754-765 (2010).

131. Johnston, SA \& May, RC. Cryptococcus interactions with macrophages: evasion and manipulation of the phagosome by a fungal pathogen. Cell Microbiol. 15, 403-411 (2013).

132. Muller, $U$ et al. Abrogation of IL-4 receptor-alpha-dependent alternatively activated macrophages is sufficient to confer resistance against pulmonary cryptococcosis despite an ongoing Th2 response. Int. Immunol. 25, 456-470 (2013).

133. Huffnagle, GB, Yates, JL \& Lipscomb, MF. Immunity to a pulmonary Cryptococcus neoformans infection requires both $\mathrm{Cd} 4+$ and $\mathrm{Cd} 8+$ T-cells. J. Exp. Med. 173, 793-800 (1991).

134. van de Veerdonk, FL, Kullberg, BJ, van der Meer, JW, Gow, NA \& Netea, MG. Host-microbe interactions: innate pattern recognition of fungal pathogens. Curr. Opin. Microbiol. 11, 305-312 (2008).

135. Biondo, $\mathrm{C}$ et al. MyD88 and TLR2, but not TLR4, are required for host defense against Cryptococcus neoformans. Eur. J. Immunol. 35, 870-878 (2005).
136. Nakamura, Ket al. Limited contribution of Toll-like receptor 2 and 4 to the host response to a fungal infectious pathogen, Cryptococcus neoformans. FEMS Immunol Med. Microbiol. 47, 148-154 (2006).

137. Yauch, LE, Mansour, MK, Shoham, S, Rottman, JB \& Levitz, SM. Involvement of CD14, toll-like receptors 2 and 4, and MyD88 in the host response to the fungal pathogen Cryptococcus neoformans in vivo. Infect. Immun. 72, 5373-5382 (2004).

138. Bellocchio, $\mathrm{S}$ et al. The contribution of the Toll-like/L-1 receptor superfamily to innate and adaptive immunity to fungal pathogens in vivo. J. Immunol. 172, 3059-3069 (2004).

139. Wagner, $\mathrm{H}$. The immunobiology of the TLR9 subfamily. Trends Immunol. 25, 381-386 (2004).

140. Krieg, AM. CpG motifs: the active ingredient in bacterial extracts?. Nat. Med. 9, 831-835 (2003).

141. Nakamura, K et al. Deoxynucleic acids from Cryptococcus neoformans activate myeloid dendritic cells via a TLR9-dependent pathway. J. Immunol. 180, 4067-4074 (2008).

142. Rodrigues, ML et al. Extracellular vesicles produced by Cryptococcus neoformans contain protein components associated with virulence. Eukaryot. Cell 7, 58-67 (2008).

143. Young, M, Macias, S, Thomas, D \& Wormley, FL Jr. A proteomic-based approach for the identification of immunodominant Cryptococcus neoformans proteins. Proteomics 9, 2578-2588 (2009).

144. Chaturvedi, AK, Weintraub, ST, Lopez-Ribot, JL \& Wormley, FL Jr. Identification and characterization of cryptococcus neoformans protein fractions that induce protective immune responses. Proteomics 13, 3429-3441 (2013).

145. Areschoug, T \& Gordon, S. Scavenger receptors: role in innate immunity and microbial pathogenesis. Cell Microbiol. 11, 1160-1169 (2009).

146. Means, TKetal. Evolutionarily conserved recognition and innate immunity to fungal pathogens by the scavenger receptors SCARF1 and CD36. J. Exp. Med. 206, 637-653 (2009).

147. Qiu, $Y$ et al. Scavenger receptor A modulates the immune response to pulmonary Cryptococcus neoformans infection. J. Immunol. 191, 238-248 (2013).

148. Wormley, FL Jr, Perfect, JR, Steele, C \& Cox, GM. Protection against cryptococcosis by using a murine gamma interferonproducing Cryptococcus neoformans strain. Infect. Immun. 75, 1453-1462 (2007).

149. Wozniak, KL et al. Insights into the mechanisms of protective immunity against Cryptococcus neoformans infection using a mouse model of pulmonary cryptococcosis. PLoS One 4, e6854 (2009).

150. Yale, SH \& Limper, AH. Pneumocystis carinii pneumonia in patients without acquired immunodeficiency syndrome: associated illness and prior corticosteroid therapy. Mayo Clin. Proc. 71, 5-13 (1996).

151. Mansharamani, NG, Garland, R, Delaney, D \& Koziel, H. Management and outcome patterns for adult Pneumocystis carinii pneumonia, 1985 to 1995: comparison of HIV-associated cases to other immunocompromised states. Chest 118, 704-711 (2000).

152. Morris, A, Wachter, RM, Luce, J, Turner, J \& Huang, L. Improved survival with highly active antiretroviral therapy in $\mathrm{HIV}$-infected patients with severe Pneumocystis carinii pneumonia. AIDS 17, 73-80 (2003).

153. Radhi, S, Alexander, T, Ukwu, M, Saleh, S \& Morris, A. Outcome of HIVassociated Pneumocystis pneumonia in hospitalized patients from 2000 through 2003. BMC Infect. Dis. 8, 118 (2008).

154. Arozullah, AM et al. A new preadmission staging system for predicting inpatient mortality from HIV-associated Pneumocystis carinii pneumonia in the early highly active antiretroviral therapy (HAART) era. Am. J. Respir. Crit. Care Med. 161 (4 Pt 1), 1081-1086 (2000).

155. Mansharamani, NG, Balachandran, D, Vernovsky, I, Garland, R \& Koziel, H. Peripheral blood CD4 + T-lymphocyte counts during Pneumocystis carinii pneumonia in immunocompromised patients without HIV infection. Chest 118, 712-720 (2000).

156. Masur, $\mathrm{H}$ et al. CD4 counts as predictors of opportunistic pneumonias in human immunodeficiency virus (HIV) infection. Ann. Intern. Med. 111, 223-231 (1989).

157. Phair, J, Munoz, A, Detels, R, Kaslow, R, Rinaldo, C \& Saah, A. The risk of Pneumocystis carinii pneumonia among men infected with human immunodeficiency virus type 1. Multicenter AIDS Cohort Study Group. N. Engl. J. Med. 322, 161-165 (1990). 
158. Harmsen, AG, Chen, W \& Gigliotti, F. Active immunity to Pneumocystis carinii reinfection in T-cell-depleted mice. Infect. Immun. 63, 2391-2395 (1995).

159. Kolls, JK et al. IFN-gamma and CD8 $+\mathrm{T}$ cells restore host defenses against Pneumocystis carinii in mice depleted of CD4 $+\mathrm{T}$ cells. J. Immunol. 162, 2890-2894 (1999).

160. Harmsen, AG \& Stankiewicz, M. T cells are not sufficient for resistance to Pneumocystis carinii pneumonia in mice. J. Protozool. 38, 44S-45S (1991).

161. Vassallo, R, Thomas, CF Jr, Vuk-Pavlovic, Z \& Limper, AH. Alveolar macrophage interactions with Pneumocystis carinii. J. Lab. Clin. Med. 133, 535-540 (1999).

162. Von Behren, LA \& Pesanti, EL. Uptake and degradation of Pneumocystis carinii by macrophages in vitro. Am. Rev. Respir. Dis. 118, 1051-1059 (1978).

163. Lasbury, ME, Durant, PJ, Ray, CA, Tschang, D, Schwendener, R \& Lee, $\mathrm{CH}$. Suppression of alveolar macrophage apoptosis prolongs survival of rats and mice with Pneumocystis pneumonia. J. Immunol. 176, 6443-6453 (2006).

164. Wang, J, Gigliotti, F, Bhagwat, SP, George, TC \& Wright, TW. Immune modulation with sulfasalazine attenuates immunopathogenesis but enhances macrophage-mediated fungal clearance during Pneumocystis pneumonia. PLoS Pathogens 6, 8 e1001058 (2010).

165. Lasbury, ME, Durant, PJ, Bartlett, MS, Smith, JW \& Lee, CH. Correlation of organism burden and alveolar macrophage counts during infection with Pneumocystis carinii and recovery. Clin. Diagn. Lab. Immunol. 10, 293-302 (2003).

166. Lasbury, ME, Merali, S, Durant, PJ, Tschang, D, Ray, CA \& Lee, CH. Polyamine-mediated apoptosis of alveolar macrophages during Pneumocystis pneumonia. J. Biol. Chem. 282, 11009-11020 (2007).

167. Willment, JA \& Brown, GD. C-type lectin receptors in antifungal immunity. Trends Microbiol. 16, 27-32 (2008).

168. Ezekowitz, RA et al. Uptake of Pneumocystis carinii mediated by the macrophage mannose receptor. Nature 351, 155-158 (1991).

169. Koziel, H, Li, X, Armstrong, MY, Richards, FF \& Rose, RM. Alveolar macrophages from human immunodeficiency virus-infected persons demonstrate impaired oxidative burst response to Pneumocystis carinii in vitro. Am. J. Respir. Cell Mol. Biol. 23, 452-459 (2000).

170. Wright, TW, Johnston, CJ, Harmsen, AG \& Finkelstein, JN. Analysis of cytokine mRNA profiles in the lungs of Pneumocystis carinii-infected mice. Am. J. Respir. Cell Mol. Biol. 17, 491-500 (1997).

171. Zhang, $\mathrm{J}$ et al. Negative regulatory role of mannose receptors on human alveolar macrophage proinflammatory cytokine release in vitro. J. Leukoc. Biol. 78, 665-674 (2005).

172. Swain, SD, Lee, SJ, Nussenzweig, MC \& Harmsen, AG. Absence of the macrophage mannose receptor in mice does not increase susceptibility to Pneumocystis carinii infection in vivo. Infect. Immun. 71, 6213-6221 (2003)

173. Nelson, MP, Metz, AE, Li, S, Lowell, CA \& Steele, C. The absence of Hck, $\mathrm{Fgr}$, and Lyn tyrosine kinases augments lung innate immune responses to Pneumocystis murina. Infect. Immun. 77, 1790-1797 (2009).

174. Schmitz, J et al. IL-33, an interleukin-1-like cytokine that signals via the IL-1 receptor-related protein ST2 and induces Thelper type 2-associated cytokines. Immunity 23, 479-490 (2005).

175. Kurowska-Stolarska, M et al. IL-33 amplifies the polarization of alternatively activated macrophages that contribute to airway inflammation. J. Immunol. 183, 6469-6477 (2009).

176. Kim, HY et al. Innate lymphoid cells responding to IL-33 mediate airway hyperreactivity independently of adaptive immunity. J. Allergy Clin. Immunol. 129, 216-227. e211-216 (2012).
177. Mjosberg, JM et al. Human IL-25- and IL-33-responsive type 2 innate lymphoid cells are defined by expression of CRTH2 and CD161. Nat. Immunol. 12, 1055-1062 (2011).

178. Imai, T et al. Selective recruitment of CCR4-bearing Th2 cells toward antigen-presenting cells by the CC chemokines thymus and activationregulated chemokine and macrophage-derived chemokine. Int. Immunol. 11, 81-88 (1999).

179. Flaczyk, A, Duerr, CU, Shourian, M, Lafferty, El, Fritz, JH \& Qureshi, ST. IL-33 signaling regulates innate and adaptive immunity to Cryptococcus neoformans. J. Immunol. 191, 2503-2513 (2013).

180. Thieu, VT et al. Signal transducer and activator of transcription 4 is required for the transcription factor T-bet to promote T helper 1 cell-fate determination. Immunity 29, 679-690 (2008).

181. Kaplan, MH, Sun, YL, Hoey, T \& Grusby, MJ. Impaired IL-12 responses and enhanced development of Th2 cells in Stat4-deficient mice. Nature 382, 174-177 (1996).

182. Myers, RC, Dunaway, CW, Nelson, MP, Trevor, JL, Morris, A \& Steele, C. STAT4-dependent and -independent Th2 responses correlate with protective immunity against lung infection with Pneumocystis murina. J. Immunol. 190, 6287-6294 (2013).

183. Liew, FY, Pitman, NI \& Mclnnes, IB. Disease-associated functions of IL-33: the new kid in the IL-1 family. Nat. Rev. Immunol. 10, 103-110 (2010).

184. Brookes, MJ \& Green, JR. Maintenance of remission in Crohn's disease: current and emerging therapeutic options. Drugs 64, 1069-1089 (2004).

185. Plosker, GL \& Croom, KF. Sulfasalazine: a review of its use in the management of rheumatoid arthritis. Drugs 65, 1825-1849 (2005).

186. Liptay, S, Bachem, M, Hacker, G, Adler, G, Debatin, KM \& Schmid, RM Inhibition of nuclear factor kappa $B$ and induction of apoptosis in T-lymphocytes by sulfasalazine. Br. J. Pharmacol. 128, 1361-1369 (1999).

187. Weber, CK, Liptay, S, Wirth, T, Adler, G \& Schmid, RM. Suppression of NFkappaB activity by sulfasalazine is mediated by direct inhibition of IkappaB kinases alpha and beta. Gastroenterology 119, 1209-1218 (2000).

188. Guiducci, C, Vicari, AP, Sangaletti, S, Trinchieri, G \& Colombo, MP. Redirecting in vivo elicited tumor infiltrating macrophages and dendritic cells towards tumor rejection. Cancer Res. 65, 3437-3446 (2005).

189. Hagemann, Tet al. "Re-educating" tumor-associated macrophages by targeting NF-kappaB. J. Exp. Med. 205, 1261-1268 (2008).

190. Duluc, $D$ et al. Interferon-gamma reverses the immunosuppressive and protumoral properties and prevents the generation of human tumorassociated macrophages. Int. J. Cancer 125, 367-373 (2009).

191. Rodrigues, AP, Carvalho, AS, Santos, AS, Alves, CN, do Nascimento, JL \& Silva, EO. Kojic acid, a secondary metabolite from Aspergillus sp., acts as an inducer of macrophage activation. Cell Biol. Int. 35, 335-343 (2011).

192. Moreira, AP et al. Serum amyloid $P$ attenuates M2 macrophage activation and protects against fungal spore-induced allergic airway disease. J. Allergy Clin. Immunol. 126, 712-721. e717 (2010).

193. Dan, JM, Kelly, RM, Lee, CK \& Levitz, SM. Role of the mannose receptor in a murine model of Cryptococcus neoformans infection. Infect. Immun. 76, 2362-2367 (2008).

194. Nosanchuk, JD, Steenbergen, JN, Shi, L, Deepe, GS Jr \& Casadevall, A. Antibodies to a cell surface histone-like protein protect against Histoplasma capsulatum. J. Clin. Invest. 112, 1164-1175 (2003).

195. Shi, L et al. A monoclonal antibody to Histoplasma capsulatum alters the intracellular fate of the fungus in murine macrophages. Eukaryot. Cell 7 , 1109-1117 (2008).

196. Youseff, BH, Holbrook, ED, Smolnycki, KA \& Rappleye, CA. Extracellular superoxide dismutase protects Histoplasma yeast cells from hostderived oxidative stress. PLoS Pathog. 8, e1002713 (2012). 